\title{
Electrical Modulus and Dielectric Relaxation Studies on Solid Electrolyte System $\left(\mathrm{BiI}_{3}\right)_{0.4}-\left(\mathrm{Ag}_{3} \mathrm{PO}_{4}\right)_{0.6}$
}

\author{
AYESHA SALEEM $^{1}$ and S. AUSTIN SUTHANTHIRARAJ ${ }^{2}$ \\ ${ }^{1}$ Department of Physics, J.B.A.S. College for Women (Autonomous), \\ Chennai-600018, India \\ ${ }^{2}$ Department of Energy, University of Madras, Maraimalai Campus, \\ Guindy, Chennai-600025, India \\ ayesha_fn@yahoo.com
}

Received 4 November 2013 / Accepted 22 November 2013

\begin{abstract}
The a.c. impedance analysis technique has been used to investigate the dynamic and relaxation behavior of mobile $\mathrm{Ag}^{+}$ions in the case of the best conducting composition $\left(\mathrm{BiI}_{3}\right)_{0.4^{-}}$ $\left(\mathrm{Ag}_{3} \mathrm{PO}_{4}\right)_{0.6}$ which exhibited the highest value of electrical conductivity $\left(3.0 \times 10^{-3} \mathrm{~S} / \mathrm{cm}\right)$ at room temperature $(298 \mathrm{~K})$ among the various compositions, previously examined by the authors, within a silver ion conducting multiphase system $\left(\mathrm{BiI}_{3}\right)_{\mathrm{x}}-\left(\mathrm{Ag}_{3} \mathrm{PO}_{4}\right)_{(1-\mathrm{x})}$ (where $0.1 \leq \mathrm{x} \leq 0.9$ mole fraction). The experimental data derived from a.c. impedance measurements carried out at various frequencies ranging from $20 \mathrm{~Hz}$ to $1 \mathrm{MHz}$ over the temperature domain 298 to $433 \mathrm{~K}$ have revealed that the chosen solid electrolyte system exhibits an a.c. conductivity behavior in accordance with Jonscher's universal power law. The dielectric response and analyses of normalized impedance and modulus spectra tend to indicate the existence of more than one relaxation process occurring within the bulk material and confirm the superionic nature of the solid electrolyte sample $\left(\mathrm{BiI}_{3}\right)_{0.4}-\left(\mathrm{Ag}_{3} \mathrm{PO}_{4}\right)_{0.6}$ for feasible application in an all-solid-state electrochemical cell as well.
\end{abstract}

Keywords: Dielectric, Modulus, Relaxation, Composite electrolyte, Silver phosphate, Bismuth triiodide

\section{Introduction}

A number of ionic conductors having low ionic conductivity at room temperature are found to exhibit a superionic nature at higher temperatures with their conductivity increasing drastically in magnitude along with significant decrease in the activation energy for conduction. Several superionic systems in the form of polymers, ceramics and composites have been studied over the past few decades for various device applications. Composite materials are expected to exhibit the strength of ceramic materials ${ }^{1}$ as well as the elasticity of polymers ${ }^{2}$. With the discovery of solid electrolyte systems $\mathrm{MAg}_{4} \mathrm{I}_{5}$ (where $\mathrm{M}=\mathrm{Rb}, \mathrm{K}, \mathrm{NH}_{4}$ ) and Na- $\beta$-alumina during the year 1967 which exhibited appreciably high ionic conductivity values of the order of $10^{-1} \mathrm{~S} \mathrm{~cm}^{-1}$ at room and moderately high temperatures, there has been a tremendous spurt in the number of composite materials which could be effectively used as superionic solids ${ }^{2-3}$. Silver ion conductors have gained importance as fast ionic conductors 
since the discovery of AgI which behaves as a solid electrolyte exhibiting a conductivity of as high as $1 \mathrm{Scm}^{-1}$ at temperatures higher than room temperature ${ }^{4}$. Subsequently, several attempts have been made by researchers in order to achieve ionic conductivity data close to that of $\alpha-\mathrm{AgI}$ in a number of materials at room temperature itself. Heterogeneous doping technique has been adopted to arrive at a number of binary and ternary composite solid electrolyte systems with $\mathrm{Ag}^{+}$ions as the mobile species. Movalent $\left(\mathrm{Cu}^{+}, \mathrm{Na}^{+}, \mathrm{Li}^{+}\right)^{5-11}$ and $\operatorname{divalent}\left(\mathrm{Pb}^{2+}\right.$, $\left.\mathrm{Cd}^{2+}, \mathrm{Mg}^{2+}\right)^{12-16}$ iodide dopants have been used in various silver oxysalt and silver oxide host matrices to synthesize AgI within such composite solid electrolyte systems in order to achieve electrical conductivity at room temperature comparable to that exhibited by $\mathrm{AgI}$ at higher temperatures $\left(147{ }^{\circ} \mathrm{C}\right)$. Such silver ion composite systems developed have proved to offer potential solid electrolyte sources for the fabrication of all-solid-state batteries.

Based on an earlier effort by Takahashi et al. ${ }^{17}$ successful attempts have been made by the present authors to develop new binary composite systems using trivalent metal-iodide namely $\mathrm{BiI}_{3}$ as a dopant in two different silver oxysalt systems namely $\mathrm{Ag}_{2} \mathrm{SO}_{4}$ and $\mathrm{Ag}_{3} \mathrm{PO}_{4}$. As a consequence, detailed investigation carried out on the $\mathrm{BiI}_{3}-\mathrm{Ag}_{2} \mathrm{SO}_{4}$ binary system has already been reported recently by the authors ${ }^{18}$. Another new solid electrolyte system $\left(\mathrm{BiI}_{3}\right)_{\mathrm{x}}-\left(\mathrm{Ag}_{3} \mathrm{PO}_{4}\right)_{1-\mathrm{x}} \quad$ (where $\mathrm{x}=0.1,0.2,0.3,0.4,0.5,0.6,0.7,0.8$ and 0.9 mole fraction respectively) developed and investigated by the present authors has also been established to be superionic in nature based on electrical conductivity, structural and thermal studies reported previously ${ }^{19}$. A detailed analysis of a.c. conductivity, electrical modulus and dielectric properties of the typical sample $\left(\mathrm{BiI}_{3}\right)_{0.4}-\left(\mathrm{Ag}_{3} \mathrm{PO}_{4}\right)_{0.6}$ which yielded the highest conductivity value among the various compositions investigated is presented here.

\section{Experimental}

One of the most common and powerful techniques of electrical characterization tools namely impedance spectroscopy has been employed for understanding the complex nature of the freshly-synthesized superionic material $\mathrm{BiI}_{3}-\mathrm{Ag}_{3} \mathrm{PO}_{4}$. The electrical conductivity data obtained from complex impedance analysis has been used to take a closer look at the dynamic behavior and dielectric response of the sample. A.c. conductivity measurements were carried out on pellets prepared with the sample $\left(\mathrm{BiI}_{3}\right)_{0.4}-\left(\mathrm{Ag}_{3} \mathrm{PO}_{4}\right)_{0.6}$ as electrolyte and silver as non-blocking electrodes using a computer-controlled Hewlett-Packard model HP4284A Precision LCR meter at various temperatures of the sample ranging from room temperature $(298 \mathrm{~K})$ to $433 \mathrm{~K}$.

\section{Results and Discussion}

\section{A.C. conductivity spectra}

Figure 1 shows the frequency dependence of electrical conductivity obtained at selected temperatures of 298, 313, 323, 333, 343, 353 and $363 \mathrm{~K}$. There are apparently three distinct regions namely a low frequency dispersion region which may be attributed to the effects of polarization taking place at the electrode and electrolyte interface and secondly a plateau corresponding to the frequency-independent conductivity or dc conductivity, $\sigma_{\mathrm{o}}$, followed by the high-frequency dispersion region ${ }^{20-21}$. At all temperatures, a drop in conductivity is clearly seen as the frequency decreases which may be attributed to an increased accumulation of charges at the electrode-electrolyte interface. At high frequencies, the periodic reversal of the applied alternating field does not favor the accumulation of charges at the interface and hence conductivity increases rapidly with increasing frequency resulting in the observed dispersion which is characteristic of a multiphase system. A careful examination of the conductivity spectra obtained at various temperatures in the case of the sample $\left(\mathrm{BiI}_{3}\right)_{0.4}-\left(\mathrm{Ag}_{3} \mathrm{PO}_{4}\right)_{0.6}$ reveals a behavior similar to the one proposed by Jonscher's power law for a superionic solid. 


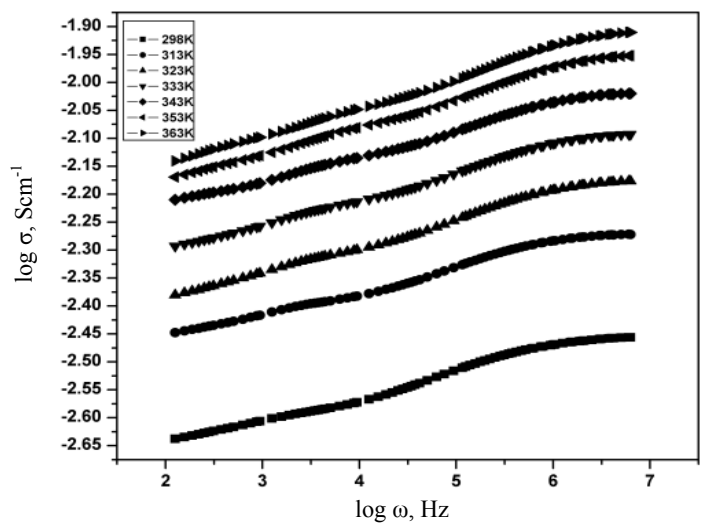

Figure 1. Conductivity spectra obtained for the solid electrolyte material $\left(\mathrm{BiI}_{3}\right)_{0.4}-\left(\mathrm{Ag}_{3} \mathrm{PO}_{4}\right)_{0.6}$

$$
\sigma_{a c}(\omega)=\sigma_{o}+A \omega^{\prime \prime}
$$

Where $A$ is a pre-exponential constant, $\omega=2 \pi \mathrm{f}$ is the angular frequency, $\sigma_{0}$, dc conductivity and $\mathrm{n}$ is the power law exponent with the limitation $0<\mathrm{n}<1$. The fitting parameters $\mathrm{A}$ and $\mathrm{n}$ have been evaluated and tabulated in Table 1. Both $\mathrm{A}$ and $\mathrm{n}$ are found to be temperature-dependent and their values contribute significantly in understanding the conduction mechanism within the sample under study. The decrease in the value of $n$ with increasing temperature indicates a gradual opening up of channels which may provide a more flexible structure within the sample for faster ionic movement thus resulting in an increased ionic conductivity ${ }^{22}$. The dc conductivity value $\sigma_{\mathrm{o}}$ has been evaluated by the extrapolation of the frequency-independent plateau region towards the $Y$-axis in the above conductivity plots. The $\sigma_{\mathrm{o}}$ value obtained at room temperature $(298 \mathrm{~K})$ is found to lie close to that estimated from impedance analysis and reported earlier by the authors ${ }^{19}$.

Table 1. The de conductivity and fitting parameters of Jonscher's power law obtained from the conductivity spectra and conductivity values obtained from the complex impedance plots for the composition $\left(\mathrm{BiI}_{3}\right)_{0.4}-\left(\mathrm{Ag}_{3} \mathrm{PO}_{4}\right)_{0.6}$

\begin{tabular}{ccccccc}
\hline $\mathrm{T}(\mathrm{K})$ & $\begin{array}{c}\sigma_{\mathrm{o}} \times 10^{-3} \\
\mathrm{~S} / \mathrm{cm}\end{array}$ & $\begin{array}{c}\mathrm{A} \mathrm{S} \mathrm{cm}^{-1} \\
\mathrm{rad}^{-\mathrm{n}} \mathrm{s}^{\mathrm{n}}\end{array}$ & $\mathrm{n}$ & $\begin{array}{c}\omega_{\mathrm{p}}=\left[\sigma_{\mathrm{o}} / \mathrm{A}\right]^{1 / \mathrm{n}} \\
\mathrm{rad}^{\mathrm{n}} \mathrm{s}^{-\mathrm{n}}\end{array}$ & $\begin{array}{c}\text { Relaxation } \\
\text { time sec }\end{array}$ & $\begin{array}{c}\sigma_{\mathrm{dc}} \text { from } \\
\text { impedance plots } \\
\times 10^{-3} \mathrm{~S} / \mathrm{cm}\end{array}$ \\
\hline 298 & 2.6 & $8 \times 10^{-7}$ & 0.51 & $7.69 \times 10^{6}$ & $1.3 \times 10^{-7}$ & 3 \\
313 & 4.1 & $4 \times 10^{-6}$ & 0.41 & $2.2 \times 10^{7}$ & $4.5 \times 10^{-8}$ & 4.5 \\
323 & 5.1 & $1 \times 10^{-5}$ & 0.35 & $5.44 \times 10^{7}$ & $1.8 \times 10^{-8}$ & 5.5 \\
333 & 6.1 & $3 \times 10^{-5}$ & 0.29 & $9.11 \times 10^{7}$ & $1.1 \times 10^{-8}$ & 6.7 \\
343 & 7.4 & $7 \times 10^{-5}$ & 0.23 & $6.32 \times 10^{8}$ & $1.58 \times 10^{-9}$ & 7.9 \\
353 & 8.5 & $16 \times 10^{-3}$ & 0.19 & $1.2 \times 10^{9}$ & $8.3 \times 10^{-10}$ & 9 \\
363 & 9.1 & $41.4 \times 10^{-3}$ & 0.13 & $2.11 \times 10^{10}$ & $4.74 \times 10^{-11}$ & 9.7 \\
\hline
\end{tabular}

The values of dc conductivity as determined from the conductivity plots at selected higher temperatures are also found to be in good agreement with those obtained from corresponding impedance plots analyzed using Boukamp equivalent circuit software. The characteristic frequency $\omega_{\mathrm{p}}$ at which dispersion begins at high frequencies and the corresponding relaxation time have also been evaluated from the conductivity spectra at different temperatures ${ }^{23}$. It is found that the hopping frequency increases with increase in temperature thus confirming that $\omega_{\mathrm{p}}$ is thermally-activated. 


\section{Impedance and modulus spectra}

The normalized complex impedance spectra obtained for the best conducting composition $\left(\mathrm{BiI}_{3}\right)_{0.4}-\left(\mathrm{Ag}_{3} \mathrm{PO}_{4}\right)_{0.6}$ at selected temperatures are shown in Figure 2. It is observed that as the temperature increases, the position of peak in the high frequency region is found to shift towards higher frequencies suggesting the existence of a distribution of relaxation times within the solid electrolyte system. The low frequency peaking may be attributed to the electrode polarization and grain-boundary effects.

Figure 3 shows the normalized modulus spectra observed as a function of temperature. A long tail in the low frequency region is observed which may be due to the large capacitance associated with the electrodes ${ }^{24}$. Further, the peaking on the high frequency side may be ascribed to the effect of the bulk material with the maxima occurring beyond the frequency range of investigation. It is also seen that the modulus curves obtained at different temperatures overlap suggesting that the distribution of relaxation times is independent of temperature ${ }^{25}$.

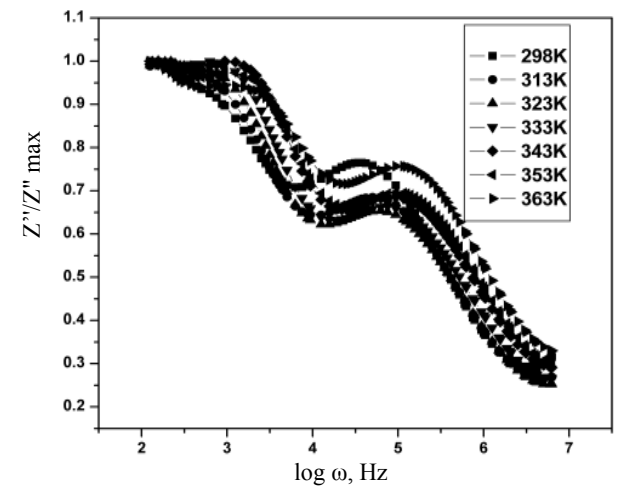

Figure 2 Normalised impedance spectra obtained for the solid electrolyte $\left(\mathrm{BiI}_{3}\right)_{0.4^{-}}$ $\left(\mathrm{Ag}_{3} \mathrm{PO}_{4}\right)_{0.6}$ at different temperatures

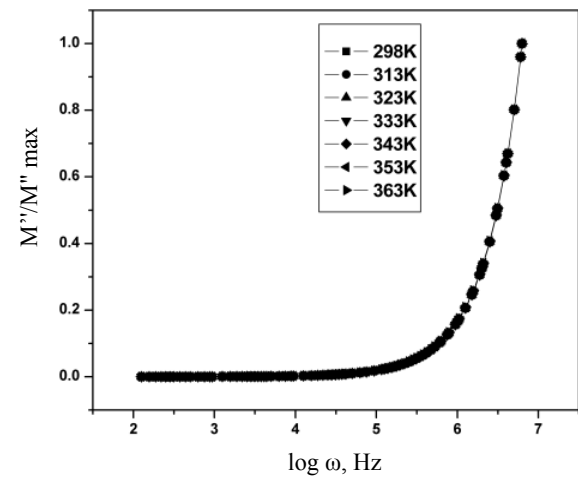

Figure 3 Normalised modulus spectra obtained for the solid electrolyte $\left(\mathrm{BiI}_{3}\right)_{0.4^{-}}$ $\left(\mathrm{Ag}_{3} \mathrm{PO}_{4}\right)_{0.6}$ at different temperatures

\section{Dielectric studies}

The dielectric property of the best conducting composition $\left(\mathrm{BiI}_{3}\right)_{0.4}-\left(\mathrm{Ag}_{3} \mathrm{PO}_{4}\right)_{0.6}$ of the already established polycrystalline superionic system, $\mathrm{BiI}_{3}-\mathrm{Ag}_{3} \mathrm{PO}_{4}$, has been analyzed at selected temperatures with reference to variation of the real component, $\varepsilon$ ' and imaginary component, $\varepsilon "$, of the complex dielectric permittivity and dielectric loss over the whole experimental frequency range of $20 \mathrm{~Hz}^{-1} \mathrm{MHz}$.

It may be clearly seen from Figure 4 that the dielectric constant decreases exponentially with frequency and becomes almost constant at very high frequencies. At a high temperature and low frequency the large value of dielectric constant may be due to ionic migration ${ }^{26}$. As the temperature increases the value of the dielectric constant is found to increase at low frequencies thus indicating the contribution of different polarizations towards the conductivity in the highly-disordered solid system. As the frequency increases the value of dielectric constant decreases and is found to become almost independent of temperature at higher frequencies which may be attributed to ionic polarization ${ }^{27}$. A similar response has been observed with dielectric loss as shown in Figure 5. 


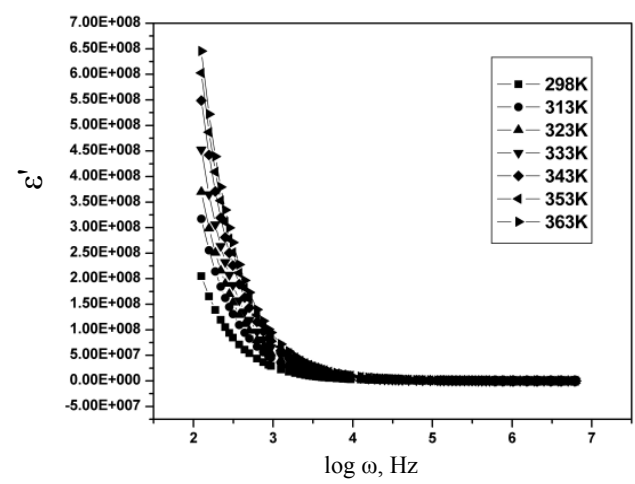

Figure 4. $\varepsilon$ ' $v s . \log \omega$ plots for the solid electrolyte $\left(\mathrm{BiI}_{3}\right)_{0.4}-\left(\mathrm{Ag}_{3} \mathrm{PO}_{4}\right)_{0.6}$ at different temperatures

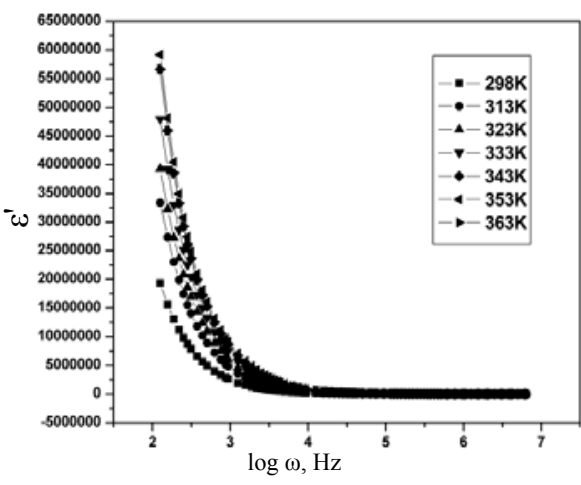

Figure 5. $\varepsilon " v s . \log \omega$ plots for the solid electrolyte $\left(\mathrm{BiI}_{3}\right)_{0.4}-\left(\mathrm{Ag}_{3} \mathrm{PO}_{4}\right)_{0.6}$ at different temperatures

\section{Loss tangent}

The dependence of the dielectric loss tangent $(\tan \delta$ ) on frequency for three different compositions (i.e. $\mathrm{X}=0.6,0.5,0.4$ and 0.3 mole fraction) of the dopant $\mathrm{BiI}_{3}$ in the host material $\mathrm{Ag}_{3} \mathrm{PO}_{4}$ is shown in Figure 6. As the concentration of $\mathrm{Ag}_{3} \mathrm{PO}_{4}$ is increased in the composite system $\mathrm{BiI}_{3}-\mathrm{Ag}_{3} \mathrm{PO}_{4}$, it is observed that in the high frequency region, the dielectric loss tangent decreases and shows the least value for the composition with 0.6 mole percent of $\mathrm{Ag}_{3} \mathrm{PO}_{4}$ content at higher frequencies which lies within the measured frequency limit thereby ascertaining the high electrical conductivity recorded by the best conducting composition analyzed. Figure 7 shows $\tan \delta v s$. $\log \omega$ curves for the best conducting composition at different selected temperatures wherein two distinct relaxation peaks are seen, one in the low frequency region and another in the high frequency region. The low frequency peak may be attributed to the grain boundary and electrode effect whereas the high frequency peak may be associated with the bulk relaxation ${ }^{28}$. The maxima of $\tan \delta$ in the bulk material appear to shift towards higher frequency indicating a decrease in the value of relaxation time and hence the height of the peak increases with increasing temperature. The dielectric relaxation phenomenon occurring within the bulk material is therefore found to be of the non-Debye type and may be due to the many-body interactions involved within the ionic conductor ${ }^{29}$.

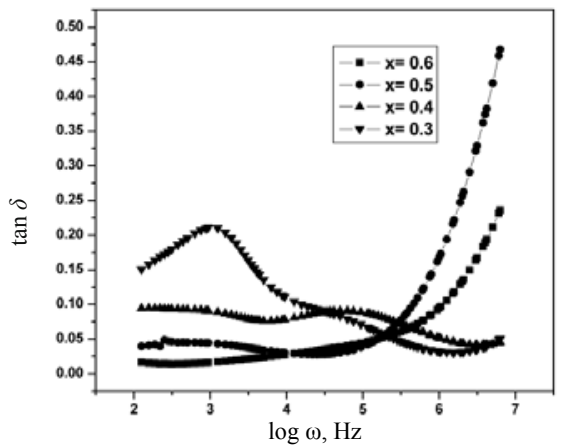

Figure 6. $\tan \delta v s . \log \omega$ plots for the solid electrolyte system $\left(\mathrm{BiI}_{3}\right)_{\mathrm{x}}-\left(\mathrm{Ag}_{3} \mathrm{PO}_{4}\right)_{1-\mathrm{x}}$ $(\mathrm{x}=0.6,0.5,0.4$ and 0.3 mole fraction $)$

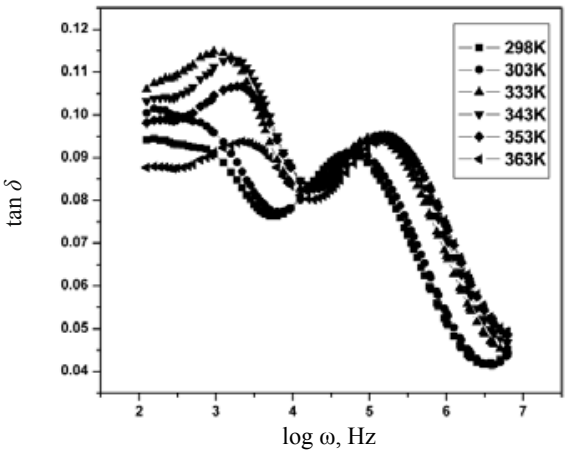

Figure 7. $\tan \delta v s . \log \omega$ plots for the solid electrolyte $\left(\mathrm{BiI}_{3}\right)_{0.4}\left(\mathrm{Ag}_{3} \mathrm{PO}_{4}\right)_{0.6}$ at different temperatures 


\section{Conclusion}

The dielectric response of the typical solid electrolyte system $\left(\mathrm{BiI}_{3}\right)_{0.4}-\left(\mathrm{Ag}_{3} \mathrm{PO}_{4}\right)_{0.6}$ suggests a non Debye-type of relaxation mechanism resulting from a distribution of relaxation times. Inferences from impedance and modulus spectra suggest that the prepared sample may be considered as a potential solid electrolyte material for the fabrication of an all-solid-state electrochemical device.

\section{References}

1. Dudek M, Int J Electrochem Sci., 2012, 7, 2874-2889.

2. $\quad$ Agrawal R C and Gupta R K, J Mater Sci., 1999, 34(6), 1131-1162;

DOI:10.1023/A:1004598902146

3. Arof A K and Radhakrishna S, Trends in Materials Science, Radhakrishna S, (Eds.) Narosa Publishing House, New Delhi, 1997, 83; ISBN-10: 81-7319-197-2

4. Chandra S, Superionic Solids-Principles and Applications; North-Holland Publishing Company: New York, 1981, Chapter 2.

5. Viswanathan A and Suthanthiraraj S A, Solid State Ionics, 1993, 62(1-2), 79-83; DOI:10.1016/0167-2738(93)90254-Z

6. Suthanthiraraj S A and Mala R, Solid State Ionics, 2001, 144(1-2), 143-149; DOI:10.1016/S0167-2738(01)00905-5

7. Suthanthiraraj S A, Murugesan S and Maruthamuthu P, Mater Sci Eng., 2002, B94(2-3), 207-213; DOI:10.1016/S0921-5107(02)00081-8

8. Chandrasekhar V G and Suthanthiraraj S A, Solid State Ionics, 1993, 62(1-2), 61-67; DOI:10.1016/0167-2738(93)90252-X

9. Suthanthiraraj S A and Premchand Y D, J Solid State Chem.. 2004, 177(11), 4126-4135; DOI:10.1016/j.jssc.2004.07.053

10. Rajendran S, Ahamed A Z, Micheal M S, Gangadharan R, Prabaharan S R S and Subramanian V, Bull Electrochem., 1996, 12(11-12), 674.

11. Sulaiman M, Rahman A A and Mohamed N S, International Proceedings of Chemical, Biological \& Environmental Engineering, Singapore, 2012, 38.

12. Selvasekarapandian S and Nalini B, Solid State Ionics, 1996, 86-88(1), 251-256; DOI:10.1016/0167-2738(96)00096-3

13. Suthanthiraraj S A and Mathew V, Ionics, 2008, 14(1), 79-83;

DOI:10.1007/s11581-007-0151-6

14. Suthanthiraraj S A and Ganeshkumar A C, Mater Sci Eng., 2003, B100(2), 156-162; DOI:10.1016/S0921-5107(03)00091-6

15. Padmasree K P, Kanchana D K, Panchala H R, Awasthi A M and Bharadwaj S, Solid State Commun., 2005, 136(2), 102-107; DOI:10.1016/j.ssc.2005.06.011

16. Mazdida S, Rahman A A and Mohamed N S, Int J Electrochem Sci., 2013, 8, 6647-6655.

17. Takahashi H, Nakanii H and Sakuma T, Solid State Ionics, 2005, 176(11-12), 10671072; DOI:10.1016/j.ssi.2005.01.007

18. Suthanthiraraj S A and Ayesha Saleem, Adv Mater Res., 2012, 584, 521-252.

19. Suthanthiraraj S A and Ayesha Saleem, Proceedings of the National Seminar on Technologically Important Crystalline and Amorphous Solids, Kalasalingam University, Krishnankoil, India, 2012, 43.

20. Mariappan C R, Govindaraj G, Vinoth Rathan S and Vijaya Prakash G, Mater Sci Eng., 2005, 123B(1), 63-68; DOI:10.1016/j.mseb.2005.06.022

21. Almond D P, Hunter C C and West A R, J Mater Sci., 1984, 19(10), 3236-3248; DOI:10.1007/BF00549810 
22. Henn F, Giuntini C and Zanchetha J V, J Non-Cryst Solids, 1991, 131-133, 1084.

23. Derek C S, Bol Soc Esp Cerám Vidrio., 1995, 34(2), 55.

24. Hodge I M, Ingram M D and West A R, J Electroanal Chem., 1976, 74, 125.

25. Gogulamurali N, Suthanthiraraj S A and Maruthamuthu P, Solid State Ionics, 1996, 86-88(2), 1403-1407; DOI:10.1016/0167-2738(96)00321-9

26. MadhavaRao M V, Narender Reddy S and Sadananda C A, J Non Cryst Solids, 2006, 352(2), 155-159; DOI:10.1016/j.jnoncrysol.2005.11.011

27 Madhava Rao M V, Narender Reddy S, Sadananda C A and Shahi K, Physica B, 2005, 364, 306-310.

28 Padmasree K P, Montalvo-Lozano R A, Montemayor S M and Fuentes A F, $J$ Alloys Compd., 2011, 509(34), 8584-8589; DOI:10.1016/j.jallcom.2011.06.036

29 Jonscher A K, Nature, 1977, 267, 673-679; DOI:10.1038/267673a0 